\title{
Outsourcing of Information Systems Functions in Small and Medium Sized Enterprises: A Test of a Multi- Theoretical Model
}

This paper, selected for the category "Best papers from 1959 to 2008", was first published in WIRTSCHAFTSINFORMATIK 43(4)2001:339-350 and has been revised for reprint.

The paper examines the situation of information systems (IS) outsourcing in a business sector intrinsic to small and medium sized enterprises (SMEs). A survey among German SMEs in a specific manufacturing industry yielded the following results: Overall, the share of IS outsourcing in SMEs may be categorized as moderate. The IS functions in SMEs are selectively outsourced, i. e., the degree of outsourcing varies across different IS functions. Whereas applications development makes up the largest share, planning and management tasks/functions remain mostly within the boundaries of the firm. An assessment of internal resource deficits vis-à-vis external service providers establishes the predominant determinant which explains the varying degrees of outsourcing IS functions. Contrastingly, transaction costs and an assessment of the strategic significance of the respective IS functions seem to play a subordinate role.

DOI 10.1007/s12599-008-0008-1

\section{The Authors \\ Dr. Jens Dibbern \\ Prof. Dr. Armin Heinzl \\ Department of Information Systems I \\ University of Mannheim \\ Schloss \\ 68131 Mannheim \\ Germany \\ \{dibbern | heinzl\}@uni-mannheim.de}

This article is also available in German in print and via http://www.wirtschafts informatik.de: Dibbern J, Heinzl A (2008) Outsourcing der Informationsverarbeitung im Mittelstand: Test eines multitheoretischen Kausalmodells. WIRTSCHAFTSINFORMATIK. doi: 10.1007/11576-008-0113-2.

\section{Introduction}

In 1987, Dearden proposed that the inhouse information systems (IS) function would cease to exist (Dearden 1987). He argued that external providers are in a position to specialize in certain services in the IS area. They would, thereby, achieve advantages in quality and costs over services provided in-house. Accordingly, it would just be a matter of time that the transition of internal IS functions to legally independent service providers would take place along with the establishment of a market for external providers. Only those firms in business sectors with a large capacity for IS would be excluded from this outsourcing trend. For these firms, Dearden predicted an increasing independence and market orientation of the IS department in the form of profit centers which are linked to the firm by capital (e. g., subsidiary or associated firms). With regard to this governance mode, one speaks of spin-offs (Heinzl 1993; Heinzl and Stoffel 1993), where the ownership remains at the parent firm. When taking stock of the IS outsourcing landscape today, it becomes clear that Dearden's predictions have only partially become true.

First of all, there is no clear evidence that large organizations or IT-intensive business sectors show a higher tendency towards captive as opposed to non-captive outsourcing arrangements. It is true that, for example, in Germany - as opposed to countries like the USA or Great Britain - the outsourcing market developed slower. ${ }^{1}$ Outsourcing was dominated by spin-off arrangements in the early 1990s (Heinzl 1993). However, this has changed over time. Many of the former spin-off arrangements were taken over by large service providers (e. g. Debis Systems House, a former spin off from Daimler, was taken over by T-Systems, or, as another example, ThyssenKrupp Information Services - later Triaton - was taken over by Hewlett Packard) (Dernbach 1997). Today, IS outsourcing to external service providers has become a widely accepted alternative to insourcing and captive outsourcing in German organizations (Lucacs 1998). Moreover, large scale outsourcing deals, which were mostly absent in the $90 \mathrm{~s}$, are beginning to gain momentum in Germany. For example, Deutsche Leasing AG signed a \$120 million deal with Computer Sciences Corporation, where CSC took over all information technology ser-

\footnotetext{
According to a market survey conducted by IDC (Murphy et al. 1999) IT-Outsourcing in the USA amounted to 13 billion US\$ in 1966 and increased to 20.5 billion in 1998. Up to 2003 an annual growth of $13.1 \%$ is predicted, corresponding to a volume of 38 billion US\$ in 2003. The evolution of the outsourcing market in Germany shows a market volume of 1.7 billion US\$ as compared to 1.3 billion in 1996 (Lucacs 1998). This reflects a relation USA:Germany of $12: 1$ which can be adjusted in regard of gross national products and proportional IT-expenditures $(4: 1)$ to a relation of 3:1 (OECD 2000).
} 


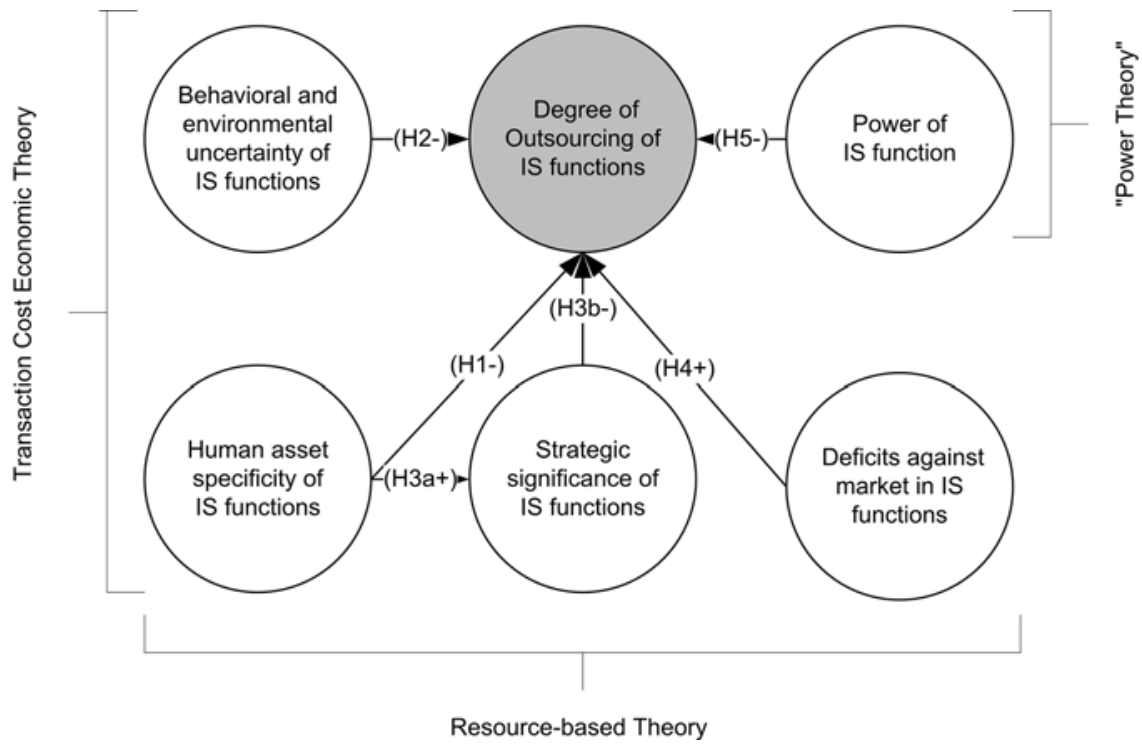

Fig. 1 Theoretical framework of IS outsourcing

vices for Deutsche Leasing, including the transfer of all its computer assets and 35 staff members to CSC.

In spite of the increasing number of IS outsourcing deals worldwide (Lucacs 1998; Murphy et al. 1999), however, the in-house IS function has not disappeared. Indeed, most organizations that opt for outsourcing do so selectively. That is, rather than outsourcing their entire IS function, they only outsource particular IS functions such as data center operations or systems development to external providers, either in part or in their entirety. This phenomenon of selective outsourcing has been substantiated by numerous empirical studies in Anglo-American regions (Grover et al. 1994; Lacity and Hirschheim 1993; Lacity et al. 1996; Sobol and Apte 1995; Willcocks et al. 1996). Moreover, Apte et al. (1997) were able to show that the respective shares of outsourcing of various IS functions differed not only in the USA but also in Japan and Finland. In a like vein, a European-wide study by IDC revealed that outsourcing behavior in Germany can, for the most part, be described as a selective approach (Lucacs 1998).

The phenomenon of selective IS outsourcing raises the question for the determinants of IS outsourcing. This question has been addressed by a significant number of studies on IS outsourcing (Ang and Cummings 1997; Ang and Straub 1998; Aubert et al. 1996; Loh and Venkatraman 1992; Nam et al. 1996; Poppo and Zenger 1998; Teng et al. 1995). However, only few studies have asked whether there are any differences between the determi- nants of IS outsourcing of certain IS functions (Teng et al. 1995). This has motivated us to reexamine the outsourcing decision with a special focus on selective outsourcing. Moreover, this research seeks to contribute to close a second research gap. It is striking that almost the entire stream of research has focused on studying the sourcing behavior of large firms, such as the Fortune 500. There is hardly any empirical evidence about the outsourcing decision of small and medium sized enterprises (SMEs). The recognition of SMEs appears to be particularly wanted in countries such as Germany, where SMEs play a significant role in the economy (Clemens et al. 2001). Accordingly, the following two research questions will guide our research:

1. To what extent are individual IS functions outsourced by SMEs in Germany?

2. Which determinants are responsible for explaining the variation in the extent to which particular IS functions are outsourced in SMEs?

In the following, a theoretical framework will be developed which hypothesizes about the determinants of selective IS outsourcing behavior of firms. The framework will then be transformed into a structural equation model and will be empirically tested using a SME sample.

\section{Theoretical Framework}

Based on an analysis of the theory of the firm, transaction cost economic (TCE) theory and resource-based theory may be adapted as complementary explanatory approaches to selective IS outsourcing (Dibbern et al. 2001; Duncan 1998). ${ }^{2}$ Both theories are similar in that they attribute rationality to management, which - though limited rational or experience-based - focuses on gaining profits or pursuing economic benefits. Not all IS outsourcing decisions, however, may result from a strictly rational decision process. In 1969, Heinrich had already taken the view that the evaluation of non-quantifiable goals, such as an increase in power, must be considered when evaluating the options of internal versus external provision of IS (Heinrich 1969). The importance of power in IS outsourcing decisions was substantiated by Lacity and Hirschheim (1993) in their multiple case study on outsourcing. They were the first that applied power theory in the IS outsourcing context and found partial support for the notion that power and politics have an influence on IS outsourcing decisions. ${ }^{3}$ Accordingly, we recognize the power aspect beyond economic and strategic considerations in developing our theoretical framework on selective outsourcing, as depicted in Fig. 1. Subsequently, each of the six hypotheses $\left(\mathrm{H}^{\star}\right)$ will be derived from the three selected theoretical lenses.

\subsection{Transaction Cost Economic Theory}

The constructs of environmental and behavioral uncertainty as well as human asset specificity are derived from TCE. According to this theory, the question of external or internal provision of services (i. e., market versus hierarchy) is decided on the basis of a cost comparison which takes into account the sum of transaction and production costs (Williamson 1975, 1981, 1985, 1990). For the purpose of this paper, transaction costs are understood as all costs of planning, adapting, and monitoring task completion within the individual IS functions under alternative governance modes (Williamson 1981, p. $552 \mathrm{f}$ ). These costs are determined by contingency factors such as the degree of environmental and behavioral uncertainty as well as asset specificity. 
Williamson describes asset specificity as the extent to which physical or human assets cannot generate the same added value outside the boundaries of the firm as inside (Williamson 1990, p. 142). In the IS context, physical or tangible assets refer to all types of information technologies, such as hardware products, information and communication technological infrastructures, as well as standard software products, which may be acquired from the market. These assets usually have little potential for variation in specificity. They can usually be applied in the same or in a similar manner by other organizations. Thus, there is no conclusive evidence that they per se could be of high firm specificity.

By contrast, human IS assets may significantly differ in their level of specificity - both between IS functions as well as between organizations. Following Williamson (1981, p. 563), necessary and sufficient conditions of human asset specificity need to be distinguished. The intellectual abilities as well as special capabilities (e.g. programming capabilities) of IS professionals can be acquired autodidactically or through training. They are necessary for performing IS services, but not sufficient to be specific to a particular organization. Sufficient criteria are those that make the capabilities unique and valuable for a single organization. This is particularly the case if IS professionals have knowledge of unique processes and procedures of an organization that can only be acquired through a "learning-by-doing" process within the served organization (Williamson 1981, p. 563). In understanding how such unique knowledge can be formed, it is important to recognize the cross-sectional nature of the IS function. Today, IS are an integral part of nearly every business process of an organization. Consequently, IS professionals need to have a certain level of understanding of the business functions that they serve. Thus, the extent to which it is required for an IS professional to build up knowledge about unique business processes and user requirements provides a good estimate for the extent of human asset specificity. Moreover, it is often not sufficient to understand particular business functions but rather to understand the flow of information between different business functions as well as the logic of inter-organizational tasks (Heinzl 1996, p. $280 \mathrm{ff}$ ). From an organizational point of view this is reflected by the frequency of cross-functional team and project work (Krcmar 1997, p. 243 ff).

It can be argued that the initiation and adaptation costs for IS functions characterized by high specificity of human capital are higher for an external provider than they are within the firm itself. An external provider must first learn to understand the complex relationship networks and interdependencies of the client organization. Presumably, an external provider would be unwilling to make these upfront specific investments, since they prevent him from realizing economies of scale. Moreover, he would behave opportunistically in this situation, i. e., he would cunningly use every opportunity to overcompensate for his specific investments at the expense of his client. Safeguarding against such behavior would result in significant transaction costs. Therefore, the following hypothesis is deduced:

$\mathrm{H} 1$ : The higher the degree of human asset specificity of an IS function, the less likely it is to be outsourced.

A second essential determinant in the "make-or-buy" decision, based on TCE theory, is uncertainty. It is impossible for a limited rational decision maker to incorporate all eventualities in the contract with an external provider. When a contract is set up, a certain deficit of information exists with regard to future changes in the requirements on the object of the contract (i. e., the IS service or product), e. g., due to new technological developments and business changes (environmental uncertainty). It can be argued that the future demands on IS functions, which are strongly influenced by technological change and innovation, can only be vaguely specified in contracts. The effects are high levels of uncertainty in the formulation of a contract and, as a result thereof, the possibility of high post-contractual adaptation costs (Lacity et al. 1995). On the other hand, the reactions of the contractual partner in critical situations (behavioral uncertainty), which could be brought about by the aforementioned environmental influences, cannot be anticipated. The behavioral uncertainty reflects the potential of opportunistic behavior of an external provider. The following hypothesis may therefore be put forward:

$\mathrm{H} 2$ : The higher the degree of environmental and behavioral uncertainty with regard to an IS function, the less likely it is to be outsourced.

\subsection{Resource-based Theory}

TCE theory implicitly assumes, however, that the market generally is capable of providing benefits or services in the same manner and quality as the firm itself (Conner 1991; Demsetz 1991; Foss 1996; Langlois 1995). The enterprise is viewed as a unit without a past. This static approach is contrary to the dynamic view of the firm furnished by the resource-based theory (Knudsen 1995). It provides reference points for when resources are to be kept and expanded within the firm for strategic reasons and when they should be brought in from an external provider. Crucial for this consideration is, on the one hand, the analysis of the basic physical and human resources, given the question of whether they can generate a sustained competitive advantage. This condition is fulfilled in particular when dealing with firm specific resources which cannot be traded, imitated, or substituted (Dierickx et al. 1989, p. $1507 \mathrm{ff}$ ).

The physical (i. e., tangible) resources of the individual IS functions, i. e., hardware and commercial software, cannot be deemed firm specific per se. Hardware components and standard software can be taken from the market at any time and can hardly be protected from imitation (Clemons and Row 1991; Mata et al. 1995). The focus, therefore, is to be placed on the human resources and capabilities within the individual functional areas. For an assessment of specificity, the same considerations are used as with "asset specificity." The constructs of specific assets and specific resources may thus be treated in an identical manner (Dibbern et al. 2001). Accordingly, the following hypothesis is stated:

H3a: The higher the degree of human asset specificity of an IS function, the higher its strategic significance.

The outsourcing of a partial function that incorporates resources and capabilities which are of strategic value to the firm ("strategic assets"), appears to make little sense (Dierickx et al. 1989, p 1505). An outsourcing contract generally stipulates that human and physical resources of a partial function are to be taken over from the external provider. However, since these resources are commonly placed into a new organizational environment, the prerequisites for expansion and new development of firm specific capabilities or core competencies are limited. Furthermore, it can be presumed that the outsourcing pro- 


\begin{tabular}{|c|c|c|c|c|}
\hline $\begin{array}{l}\text { System \& Data Center Opera- } \\
\text { tions }\end{array}$ & $\begin{array}{l}\text { Telecommunications \& } \\
\text { Networks }\end{array}$ & $\begin{array}{l}\text { Application Services (Devel- } \\
\text { opment, Implementation and } \\
\text { Maintenance) }\end{array}$ & $\begin{array}{l}\text { User Support / Help Desk / } \\
\text { Information center }\end{array}$ & $\begin{array}{l}\text { IS-Planning \& IS-Manage- } \\
\text { ment }\end{array}$ \\
\hline $\begin{array}{l}\text { Installation, operation and } \\
\text { technical maintenance of } \\
\text { centralized and decentralized } \\
\text { computers (client / server } \\
\text { systems) or systems software } \\
\text { Systems programming } \\
\text { Systems control } \\
\text { Security and catastrophe } \\
\text { prevention }\end{array}$ & $\begin{array}{l}\text { Construction, operation and } \\
\text { maintenance of networks } \\
\text { Administration (and integra- } \\
\text { tion) of data and application } \\
\text { servers (into networks). } \\
\text { Implementation and } \\
\text { operation of relevant } \\
\text { services for inter- and intra- } \\
\text { company information } \\
\text { exchange (e. g. EDI) }\end{array}$ & $\begin{array}{l}\text { Development of one's own } \\
\text { software and applications } \\
\text { System analysis } \\
\text { Project management } \\
\text { Maintenance of existing } \\
\text { applications } \\
\text { Data(base) administration } \\
\text { Quality assurance } \\
\text { Implementation and adapta- } \\
\text { tion of standard software } \\
\text { packages (e. g., SAP R/3) }\end{array}$ & $\begin{array}{l}\text { Advice and support } \\
\text { of the users } \\
\text { Training, instruction and } \\
\text { continued education of users } \\
\text { Problem management } \\
\text { Function as a bridge } \\
\text { between other departments } \\
\text { and the IS department } \\
\text { Test, procure, install, } \\
\text { introduce and maintain } \\
\text { hardware and software }\end{array}$ & $\begin{array}{l}\text { Long-term IS-planning } \\
\text { Integration of business } \\
\text { planning and IS-planning } \\
\text { Questions of principle } \\
\text { Identification of future } \\
\text { IS innovations } \\
\text { IS-Controlling } \\
\text { Conception of system } \\
\text { architecture } \\
\text { Standards and methods }\end{array}$ \\
\hline
\end{tabular}

vider will pass on firm specific knowledge of its acquired resources to his other clients - among which direct competitors of the contractual partner may be found. Thus, competitive advantages may neither be expanded nor maintained. These considerations lead to the following conclusion:

$\mathrm{H} 3 \mathrm{~b}$ : The higher the strategic significance of the resources and capabilities of an IS function, the less likely it will be outsourced.

Until now, it has either been assumed that client and vendor generally have access to the same resources and capabilities (TCE), or that the in-house provision of IS functions is superior in creating strategic benefits from IS. This view, however, neglects the fact that the market is also able to learn from the past and to develop its own capabilities and routines based on available resources (Langlois 1995, p. 92 ff). These resources can, in turn, be used by a client firm as complementary assets (Teece et al. 1994, p. 20 f; Teng et al. 1995). A firm will not make use of market competency as long as it can generate the same capabilities using internal resources. However, if deficits in resources and capabilities are diagnosed on the basis of a company's strategic orientation, the market may become an attractive alternative for the purpose of filling these gaps (Grant 1991, p. $131 \mathrm{ff).} \mathrm{The}$ larger the deficits and the less likely these gaps can be closed using the firm's own capabilities, the higher will be the attractiveness of outsourcing. These arguments lead to the following hypothesis:

H4: The greater the deficit in the firm's resources and capabilities of an IS function, the more likely it will be outsourced.

\subsection{Power Theory}

Power Theory can be understood as an expression of the behavioral theory which conceptualizes the firm as a political coalition (Cyert and March 1963). At the core of the theory is the clarification of the relationships between the interests, conflicts and power of single individuals or political coalitions within the firm (Morgan 1996, p. 148).

The interests of each individual may be reflected by the formation of various interest groups (political coalitions) within the firm. If conflicts of interest arise, the power and the politics of the individual parties serve as the ultimate medium for conflict resolution. Power may be defined as the potential of a party to influence the behavior of another party in a certain matter, whereby politics is the manner in which power is exercised (Peter 1981, p. 7; Tushman 1977, p. 207). Since the focus of this paper is on explaining variations in decision outcomes rather than in the a priori decision process, only the influences of power will be considered in the following.

It is argued that an IS department with a high level of power will seek to maintain or expand its base of power whenever possible. Presumably, the power potential is reduced with every loss of assets due to organizational changes such as rationalization, restructuring, or outsourcing. For a department with relatively little power within the firm, there is little possibility of defending itself against such processes. Indeed, there is often no incentive whatsoever for the affected departments to behave in a restrictive manner. This is often the situation when they find a higher power potential in their new position than in the original one. Accordingly, career prospects and opportunities for personal development may be more highly valued outside the firm. If the in-house department, however, offers a higher power potential then there is little likelihood that one will be better off in the new position within the hierarchy of the external service provider. In this case, resistance to outsourcing will be strong, and the power potential within the firm will be utilized to impede the process or prevent it altogether. According to the power theory, the following hypothesis regarding the outsourcing decision is put forward (Lacity and Hirschheim 1993):

H5: The greater the relative power of the IS department within the firm, the less likely it is that IS functions will be outsourced.

\section{Research Methodology}

\subsection{Data}

In order to test the hypotheses on the determinants of IS outsourcing, data was collected using a questionnaire survey. The questionnaire was pre-tested with high level executives to ensure understandability and answerability and then sent out to 281 SMEs. The original sample was made up of firms in the federal states of Bavaria (113), Baden-Wuerttemberg (95) and Hessen/Rhineland-Palatinate/Saarland (73), all of which are part of the industrial sector relating to glass, ceramics, stones, and soils (based on Hoppenstedt data base). The questionnaire was addressed to the top management (e. g. the chief executive officer (CEO)) of the SMEs. A total of 34 questionnaires were returned, which equals a response rate of $12 \%$. To ensure that the evaluated questionnaires provide a representative sample, the firms that responded immediately were compared with those that responded in a second survey round. The comparison was made using the firms' sales volume and number of employees. No significant differences could be determined between the groups (t-Test, $\mathrm{p}<0,05)$. 


\subsection{Measures}

Each construct was measured with a set of measurement items, i. e. questions. The unit of analysis for the majority of constructs was the respective IS function. Altogether five different IS functions were distinguished. Tab. 1 describes each of the functions (based on Mertens and Knolmayer 1998; Teng et al. 1995). The respondents had to answer each question for each of the five IS functions (see Poppo and Zenger 1998). Only the power items were related to the entire IS department as a unit of analysis.

The outsourcing behavior as the central dependent variable in the study was measured using a single question reflecting the percentage of the total budget for the respective IS function that is spent for outsourcing.

All of the independent variables - except for the uncertainty construct - were measured with questions or indicators that reflected the individual constructs. Due to the complexity of the construct of "behavioral and environmental uncertainty", this construct was operationalized using the so-called formative mode (Chin 1998b; Chin 1998c; Fornell 1989). This mode is based on the assumption that the individual indicators cause different outcomes of the construct. In contrast to the reflective mode, the individual indicators that together form the measurement model are assumed to be independent of each other. As such, the responsible indicators with regard to each of the five IS functions were (1) the number of suitable external providers; (2) the extent of future changes in requirements; and (3) the difficulty in measuring task performance.

Human asset specificity was reflected by the need of IS professionals in each of the IS functions (1) for knowledge about the processes and requirements of the business units, (2) for knowledge about crossfunctional and inter-organizational relationships, and the need for (3) close collaboration with the business units, e. g., in the form of teamwork or joint projects.

Strategic significance takes the role of both an independent variable in respect to IS outsourcing and a dependent variable concerning human asset specificity. It was measured as the contribution of the individual IS function to achieve a competitive advantage through (1) cost leadership, and (2) differentiation.
Resource deficits reflect the extent to which the ability of an external supplier is rated higher than one's own with regard to (1) closing current performance gaps and (2) coping with future demands in each of the individual IS functions.

Power was not related to the individual IS functions but to the IS department in its entirety. It was measured through inquiry about (1) the level of hierarchy of the IS department within the firm, and (2) the degree of financial autonomy of the IS department.

For additional descriptive characterization of the sample, four demographic variables were incorporated. The size of the entire firm was measured using (1) total sales and (2) the total number of employees. As indicators of the IS size, (3) the IS budget and (4) the number of IS employees were chosen. In order to be able to examine the relative financial importance of each IS function, the percentile share of each individual function in the total IS budget was assessed.

\subsection{Partial Least Squares Analysis}

The data analysis was performed using the component-based procedure for structural equation modeling "Partial Least Squares" (PLS) (Chin 1998c; Chin and Newsted 1999). This procedure allows testing both direct as well as indirect relationships between numerous - not directly observable - quantities (so-called latent variables or hypothetical constructs). Moreover, it allows to simultaneously assess the validity of the measurement items and the hypotheses, i. e. structural paths (as depicted in Fig. 1).

In recent years, the PLS-Method (Chin 1998c; Chin and Newsted 1999; Wold 1989), along with the usual method of covariance-based structural equation modeling (e.g., LISREL, EQS, AMOS), has increased in popularity. In addition to its greater flexibility in modeling measurement indicators (allowing to model both reflective and formative indicators), the attractiveness of the method can be attributed, among other things, to the lower requirements in sample size and data distributions. Since the construct of behavioral and environmental uncertainty has been operationalized in the formative mode and due to the small sample size of $\mathrm{n}=34$, PLS was selected as an adequate data analysis method. The significance test for all paths was performed by using the "bootstrap resampling" routine (Chin and Newsted 1999). ${ }^{4}$ To assess the validity of the reflective measures, the factor loadings and the construct reliabilities were used. In the case of formative indicators, the weights of the individual indicators were assessed following the recommendations of Chin (1998c).

In the course of data analysis, the model on the one hand, was tested using the aggregated data set including all five IS functions, which resulted in a sample size of $n=5 \times 34=170$ (see Poppo and Zenger 1998). ${ }^{5}$ On the other hand, the model for each of the individual IS functions $(n=34)$ was tested. This allowed to identify potential differences in the determinants of outsourcing across the five IS functions.

\section{Empirical Results}

\subsection{Descriptive Statistics}

The descriptive results of the study relate to the first research question that aimed to increase the knowledge base regarding the extent of IS outsourcing in SMEs. The demographics of the sample are illustrated in Tab. 2.

It is apparent that within the firms investigated, the ratio of IS expenses and total sales is quite small (mean: $0.7 \%$ ). The number of IS employees, with an average of five employees, may also be categorized as relatively small. This implies that there is a rudimentary division of labor within the IS function of SMEs.

Examining the degree of outsourcing across the individual IS functions reveals that the limited personnel resources observed in IS may not be explained by a high level of outsourcing in SMEs. Indeed, the degree of outsourcing can be considered moderate, with the means varying from $6 \%$ to $31 \%$ (see Tab. 3). The highest degree of outsourcing can be observed for the applications development and maintenance function (mean: $31 \%$ ), followed by telecommunication \& networks, system \&

\footnotetext{
4 In each case $\mathrm{N}=200$ "bootstrap-samples" were generated. This resulted in N-1 degrees of freedom. 5 Poppo und Zenger (Poppo and Zenger 1998, p. 862) applied the same aggregation in their empirical study regarding nine different IS functions: "...the core sample was nine IS functions across 152 companies for a total sample of 1368 information service exchanges." A critical remark, however, the samples are not independent because the questions regarding all IS functions were answered by only one person in each company.
} 


\begin{tabular}{llllllll}
\hline Tab.2 Demographics & & & & & & \\
Demographic Variables & Sample & Min & Max & Mean & StD & \\
& Sales in Mill. DM & 31 & 15 & 750 & $\mathbf{1 3 4}$ & 161 \\
\cline { 2 - 7 } Firm Size & Number of Employees & 33 & 25 & 1900 & $\mathbf{5 2 5}$ & 532 \\
& IS-Expenditure/Sales (\%) & 29 & 0.10 & 1.80 & $\mathbf{0 . 7 0}$ & 0.44 \\
\cline { 2 - 6 } IS Size & Number of IS Employees & 33 & 0 & 22 & $\mathbf{5}$ & 5
\end{tabular}

\begin{tabular}{|lllll|}
\hline Tab. 3 Percentage of outsourcing per IS function & & \\
\hline IS Functions & Sample & Max (\%) & Mean (\%) & StD \\
\hline System \& Data Center Operations & 33 & 100 & $\mathbf{2 3}$ & 28 \\
\hline Telecommunications \& Networks & 33 & 100 & $\mathbf{2 4}$ & 30 \\
\hline $\begin{array}{l}\text { Application Services (Development, } \\
\text { Implementation and Maintenance) }\end{array}$ & 33 & 90 & $\mathbf{3 1}$ & 32 \\
\hline Help Desk \& User Support & 33 & 90 & $\mathbf{1 8}$ & 22 \\
\hline IS-Planning \& Management & 33 & 50 & $\mathbf{6}$ & 10 \\
\hline
\end{tabular}

data center operations, user support, and IS planning \& management. A closer investigation of the relative financial importance of each IS function reveals that, on average, the highest amount of money is spent for systems operations ( $30 \%$ ), followed by application services $(27 \%)$, telecommunication \& networks (18\%), user support $(15 \%)$ and IS management (10\%).

In order to better understand the systems landscape of SMEs, a control question was asked on the types and the extent of standard software usage. Interestingly, the degree of standard software usage from external sources was quite significant. This is particularly true for administrative functions. In the fields of finance and accounting, $76 \%$ of the responding firms use standard software products, whereby the SAP R/3 package and COMET from Siemens are preferred. The use of standard software in the fields of logistics (32\%) and personnel (29\%) was less commonplace.

\subsection{Findings from Model Testing}

The model testing provides answers for the second research question on the determinants of selective IS outsourcing. Before analyzing the structural model, it is important to ensure that each block of indicators consistently measures what it is supposed to measure. Following this procedure, it became obvious that when testing the aggregated model and the five individual models for each IS function, the three formative indicators of the construct of environmental and behavioral uncertainty are partly related to the construct not only with different weights but also with different directions. This ambivalence in the formative indicators leads to the supposition that each of the indicators may not only represent different independent aspects of uncertainly but may also exert different theoretical influences on the degree of outsourcing. In order to better illustrate and understand these different impacts of the three uncertainty items, the initial model was adapted in an exploratory manner. Similar to simple regression analysis, each item was treated as a separate construct with a single measurement item. The resulting path relationships are reflected by the following three hypotheses:

H2a: The smaller the number of suitable external suppliers, the less likely an IS function will be outsourced.

$\mathrm{H} 2 \mathrm{~b}$ : The greater the change in the demands and tasks of individual IS functions, the less likely they will be outsourced.

$\mathrm{H} 2 \mathrm{c}$ : The greater the difficulty of measurement of task performance of the individual IS functions, the less likely they will be outsourced.

In this way, the explanatory power of the individual indicators can better be illustrated and falsified. Each indicator now represents an independent predictor variable. This modification of the original model structure, however, means a deviation from the original research design. It can be regarded as an exploration within the confirmatory research approach (Chin 1998a; Lee et al. 1997, p. 121).

In order to ensure measurement reliability for the adapted model, both indica- tor and construct reliability were assessed (Chin 1998c; Peter 1981). The reliability of the individual indicators per construct was assessed by examining the construct loadings. All of the loadings were above the threshold of 0.7 and highly significant at the 0.01 level except for three items that were non significant (n.s.) and two that were significant at the $0.05{ }^{(*)}$ level. Construct reliability was assessed by examining the composite reliability (CR) and the average variance extracted (AVE) for each latent variable. All of the calculated indices for the tested models were above the threshold of 0.7 for CR and 0.5 for AVE (Bagozzi and Yi 1988), except for one AVE value (0.41). Thus, overall, no systematic measurement error that occurred throughout all of the IS functions could be observed. Since the constructs "number of suppliers", "environmental changes", "measurement difficulties", and "degree of outsourcing" were measured with only one indicator, the factor loadings are excluded from the parameter estimates for these constructs and fixed at 1.0. ${ }^{6}$

The test results for the modified structural model are presented in Tab. 4. Moreover, Fig. 2 provides a graphical presentation for one selected IS function "applications development, implementation, and maintenance". The test results for each hypothesis are assigned to the respective path by including the path coefficients (standardized) together with their level of significance. ${ }^{7}$ As can be inferred from Fig. 2, only hypothesis H3a+ (strong positive relationship between human asset specificity and strategic significance) and $\mathrm{H} 4+$ (moderately strong positive relationship between resource deficits and the degree of IS outsourcing) is supported for this particular IS function. Hypotheses $\mathrm{H} 2 \mathrm{a}+$ and $\mathrm{H} 2 \mathrm{c}$ - show a reversed significant relationship. Hypotheses H1-, $\mathrm{H} 2 \mathrm{~b}-$ and H5- are insignificant. Moreover, a total of $38.2 \%$ of the variance in the dependent variable - the degree of IS outsourcing - is explained by the model.

\section{Discussion}

Overall, the results offer evidence that there are some substantial differences in the determinants of IS outsourcing

\footnotetext{
6 In this case, measurement errors that have an impact on the level of factor

loadings are not explicitly accounted for. As depicted by the asterisks.
} 
between IS functions and that the IS outsourcing decision of SMEs is strongly influenced by resource constraints rather than strategic and TCE considerations, or power aspects.

The stream of reasoning of TCE is strongly based on the view that organizations would opt for insourcing when the risk of market failure would be too high in economic terms. This risk is proposed to be particularly high if the human assets required to perform an IS function are highly firm specific and if the IS function is associated with a high level of uncertainly. Obviously, there was no direct impact of human asset specificity on the degree of outsourcing in any of the tested models (across IS functions), which implies that the economic consequences of human asset specificity are not taken into account in outsourcing decisions by SMEs.

It is interesting to note, however, that human asset specificity consistently was found to have a strong impact on the strategic significance of each of the IS functions. This means that firm specific assets, reflected by a good understanding of the idiosyncratic processes of the business units as well as cross-functional process knowledge, are important prerequisites for achieving strategic benefits from IS. The strategic impact of an IS function does not automatically mean, however, that such a function should not be outsourced (McLellan et al. 1995), as indicated by the mostly insignificant relationship between strategic significance and degree of outsourcing. Following on from this observation, it could be argued that SMEs generally put little emphasis on strategic considerations when it comes to decide on important IS issues such as outsourcing. For example, in a study on IS management in SMEs, Krcmar found the consciousness of the strategic relevance of IS to be quite low among IT directors (Krcmar 1992). Similarly, a study on IS-controlling issues in mid-sized firms clearly showed that SMEs emphasized the importance of IS on the overall firm level, however, there was very little evidence for a downstream implementation and consideration of strategic issues (Spitta 1998). In the only U.S. based empirical study on IS outsourcing in mid-sized firms to date, Borchers also determined that there was no relationship between the construct of IS as a core competency and the degree of IS outsourcing (Borchers 1996); whereas in the base

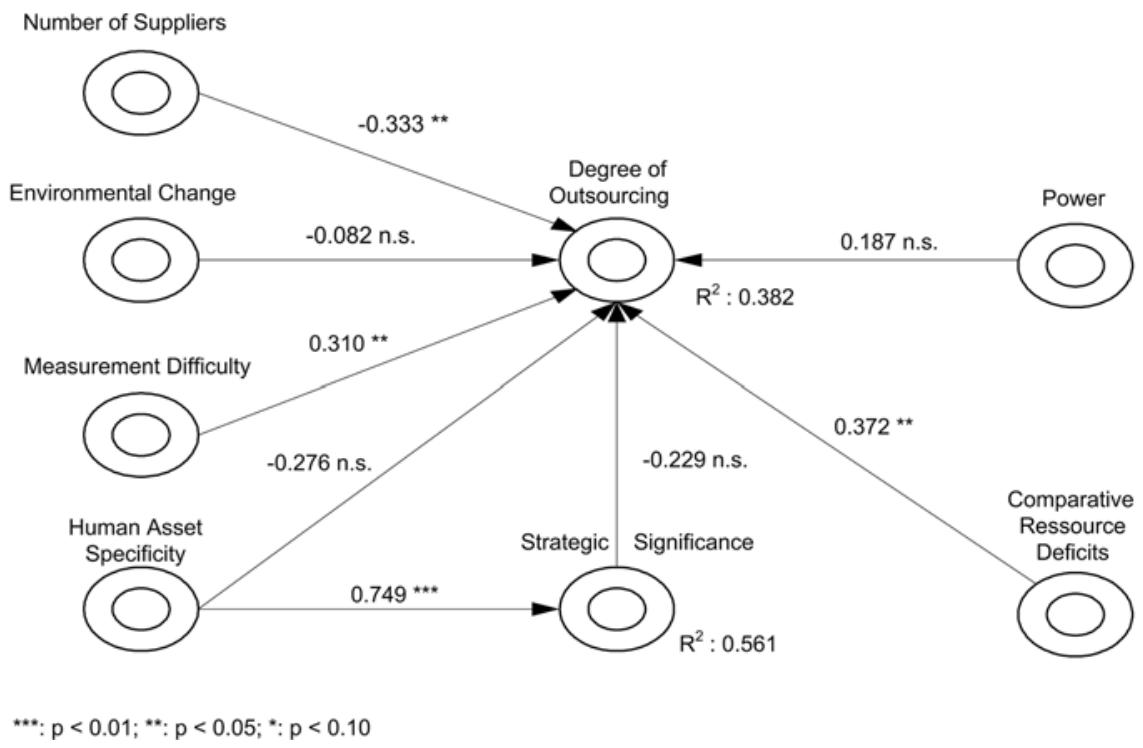

Fig. 2 Model findings for applications development, implementation, and maintenance

study by Loh (1993), whose research subjects consisted of large U.S. firms (Fortune 500), a strong negative relationship was ascertained. ${ }^{8}$

What stands out from the findings is the strong and significant impact of perceived comparative resource deficits on the degree of IS outsourcing for the majority of IS functions - except for the functions telecom \& network as well as planning \& management. In 1991, Rumelt et al. showed foresight with the view that market contracts would not only be taken into consideration when they are perceived as not to fail based on efficiency criteria but also, or even more likely, when firms or organizations themselves "fail" to adequately perform a certain task or function (Rumelt et al. 1991, p. 19).

This, obviously, is the decisive factor for the majority of sourcing decisions in the observed SMEs. Deficits in an organization's IS resources in coping with current and future requirements appear to serve as an overriding contingency (Sambamurthy and Zmud 1999) or deviant factor (Brown 1997) in many outsourcing decisions of SMEs. Based on this, the partially contradictory findings on the relationship between the constructs "number of suppliers", "measurement difficulty" and "envi-

8 Borchers (1996) states: "The concept of core competencies, while frequently mentioned in management literature and embraced in the Fortune 500 firms Loh worked with, may well be a prescription that managers in the medium sized manufacturing firms studied here have not yet come to understand and employ." ronmental change" and the degree of outsourcing become more plausible.

In terms of the negative rather than positive relationship between the number of available suppliers and the degree of outsourcing, it can be argued that SMEs outsource application services, system operations, or the help desk function despite a small number of suitable IS service providers, because, for them, the elimination of resource deficits with the help of external suppliers outweighs the danger of resource dependency on an IS service provider.

Another notion of resource deficits could be an explanation for the contradictory finding that organizations were found to outsource particular IS functions to a higher (rather than lower) extent in case they have difficulties in measuring the performance of these functions (application services, systems operations, and user support). Here, measurement difficulties may be viewed as deficits, which could more likely be eliminated by an external provider than by the firm itself. Similar results could be found in a study on spin-off arrangements, where the desire for improved monitoring and control of IS was a strong driver for spinning off the IS function. Such an interpretation is fueled by critics of TCE theory that question the supposition that the danger of opportunistic behavior could better (i. e. more efficiently) be prevented within the firm via the principle of authority and internal control mechanisms (Ghoshal and Insead 1996).

It is also interesting to note that with regard to the function telecom \& net- 


\begin{tabular}{|c|c|c|c|c|c|c|c|c|c|c|}
\hline \multirow[t]{2}{*}{ IS-Functions } & \multicolumn{8}{|c|}{ Hypotheses } & \multicolumn{2}{|l|}{$\mathrm{R}^{2}$} \\
\hline & $\begin{array}{l}\text { H1(-) } \\
\text { Asset } \\
\text { spec. }\end{array}$ & $\begin{array}{l}\mathrm{H} 2 \mathrm{a}(+) \\
\text { No. of } \\
\text { suppl. }\end{array}$ & $\begin{array}{l}\mathrm{H} 2 \mathrm{~b}(-) \\
\text { Change }\end{array}$ & $\begin{array}{l}\mathrm{H} 2 \mathrm{c}(-) \\
\text { Meas. } \\
\text { diffic. }\end{array}$ & $\begin{array}{l}\mathrm{H} 3 \mathrm{a}(+) \\
\text { Ass. sp. } \\
\text { Strat. }\end{array}$ & $\begin{array}{l}\mathrm{H} 3 \mathrm{~b}(-) \\
\text { Strat.. }\end{array}$ & $\begin{array}{l}\text { H4(+) } \\
\text { Res. def. }\end{array}$ & $\begin{array}{l}\text { H5(-) } \\
\text { Power }\end{array}$ & Strat. & Out \\
\hline Application services & $\begin{array}{l}-0.28 \\
t: 0.88\end{array}$ & $\begin{array}{l}-0.33^{* *} \\
\mathrm{t}: 1.94\end{array}$ & $\begin{array}{l}0.08 \\
t: 0.55\end{array}$ & $\begin{array}{l}0.31^{*} \\
\mathrm{t}: 1.70\end{array}$ & $\begin{array}{l}0.75^{* * *} \\
\mathrm{t}: 10.99\end{array}$ & $\begin{array}{l}-0.23 \\
\mathrm{t}: 0.89\end{array}$ & $\begin{array}{l}0.37^{* *} \\
\mathrm{t}: 1.77\end{array}$ & $\begin{array}{l}0.19 \\
\text { t: } 0.92\end{array}$ & 0.56 & 0.38 \\
\hline Systems operations & $\begin{array}{l}0.03 \\
\mathrm{t}: 0.12\end{array}$ & $\begin{array}{l}-0.07 \\
\mathrm{t}: 0.10\end{array}$ & $\begin{array}{l}-0.30^{*} \\
\text { t: } 1.38\end{array}$ & $\begin{array}{l}0.54^{* * *} \\
\mathrm{t}: 2.31\end{array}$ & $\begin{array}{l}0.355 \\
\mathrm{t}: 1.8\end{array}$ & $\begin{array}{l}0.083 \\
\mathrm{t}: 0.57\end{array}$ & $\begin{array}{l}0.26^{*} \\
t: 1.80\end{array}$ & $\begin{array}{l}0.26 \\
\mathrm{t}: 1.08\end{array}$ & 0.13 & 0.44 \\
\hline User Support & $\begin{array}{l}0.28 \\
\mathrm{t}: 1.00\end{array}$ & $\begin{array}{l}-0.29^{* *} \\
\mathrm{t}: 1.57\end{array}$ & $\begin{array}{l}0.10 \\
t: 0.54\end{array}$ & $\begin{array}{l}0.41^{* * *} \\
\mathrm{t}: 2.68\end{array}$ & $\begin{array}{l}0.61^{* * *} \\
\mathrm{t}: 7.10\end{array}$ & $\begin{array}{l}0.37^{*} \\
\mathrm{t}: 1.37\end{array}$ & $\begin{array}{l}0.44^{* * *} \\
\mathrm{t}: 2.56\end{array}$ & $\begin{array}{l}0.48^{* *} \\
\mathrm{t}: 2.09\end{array}$ & 0.38 & 0.45 \\
\hline Telecom \& Networks & $\begin{array}{l}0.058 \\
\mathrm{t}: 0.18\end{array}$ & $\begin{array}{l}-0.26^{*} \\
\mathrm{t}: 1.42\end{array}$ & $\begin{array}{l}0.24^{*} \\
\mathrm{t}: 1.44\end{array}$ & $\begin{array}{l}-0.13 \\
\mathrm{t}: 0.51\end{array}$ & $\begin{array}{l}0.43^{*} \\
\mathrm{t}: 1.54\end{array}$ & $\begin{array}{l}-0.28 \\
\mathrm{t}: 1.00\end{array}$ & $\begin{array}{l}0.18 \\
\text { t: } 0.78\end{array}$ & $\begin{array}{l}-0.22 \\
\text { t: } 0.79\end{array}$ & 0.19 & 0.21 \\
\hline Planning \& Mgmt. & $\begin{array}{l}0.22 \\
t: 0.64\end{array}$ & $\begin{array}{l}-0.08 \\
t: 0.39\end{array}$ & $\begin{array}{l}0.13 \\
\mathrm{t}: 0.52\end{array}$ & $\begin{array}{l}0.12 \\
t: 0.47\end{array}$ & $\begin{array}{l}0.41^{* * *} \\
\mathrm{t}: 2.45\end{array}$ & $\begin{array}{l}-0.28 \\
\mathrm{t}: 0.91\end{array}$ & $\begin{array}{l}0.21 \\
\mathrm{t}: 1.07\end{array}$ & $\begin{array}{l}0.27 \\
\mathrm{t}: 1.35\end{array}$ & 0.16 & 0.28 \\
\hline All IS functions & $\begin{array}{l}0.06 \\
\text { t: } 0.51\end{array}$ & $\begin{array}{l}0.05 \\
\mathrm{t}: 0.88\end{array}$ & $\begin{array}{l}0.08 \\
t: 0.38\end{array}$ & $\begin{array}{l}0.06^{*} \\
0.41\end{array}$ & $\begin{array}{l}0.56^{* * * *} \\
\mathrm{t}: 13.71\end{array}$ & $\begin{array}{l}0.09^{*} \\
\text { t: } 0.77\end{array}$ & $\begin{array}{l}0.34^{* * *} \\
\mathrm{t}: 5.32\end{array}$ & $\begin{array}{l}0.12^{* *} \\
1.32\end{array}$ & 0.31 & 0.16 \\
\hline
\end{tabular}

works, no significant relationship could be found between resource deficits and outsourcing. This observation could be related to limited experiences of SMEs with advanced information and communication technologies (at least at the time of the survey). Contrary to $\mathrm{H} 2 \mathrm{a}+$, firms prefer to outsource telecom \& network services despite a limited number of external providers and - contrary to TCE - when the degree of environmental change in the requirements and tasks of this infrastructure function is perceived to be particularly high. In this case, outsourcing may be seen as a spontaneous, unreflected reaction to an uncertain environmental situation which is caused by strong innovational forces within the IT industry. The need for adopting so-called "enabling technologies" in order to stay competitive in the market may be so strong that outsourcing is seen as a viable option to quickly follow suite (Beije 1996, p. 311).

Moreover, contrary to $\mathrm{H} 5$, power of the entire IS function had a significant positive rather than negative impact on the degree of outsourcing. That is, more power is related to more outsourcing. This observation can likely be traced back to the specific SME situation. The descriptive data has shown that the provision of personnel and financial resources for IS is limited in all of the responding firms. Therefore, it might be inappropriate to relate the power aspect only to the situation within the firm. By contrast, the possible change of power through IS outsourcing needs to be considered. With an average number of five IS employees, the career, salary, and developmental paths for IS employees are strongly restricted in SMEs. It can therefore be argued that IS professionals will tend to favor the employment at an external service provider and, accordingly, will have a positive attitude towards IS outsourcing even if they have a relatively high power level within the firm.

Finally, it is evident that the model's explanatory power relating to the function planning and management is low. The decisive aspects for keeping this function within the boundaries of the firm obviously lie outside of the explanatory realm of the model. In particular, the aspects of coordination and control of an external service provider as well as the retention of capabilities for self-accentuation and direction in IS could prove relevant.

\section{Summary and Outlook}

This paper has focused on the situation of IS outsourcing in a specific manufacturing industry with a relatively high amount of SMEs. The results have shown that the SMEs spent relatively little money on IS and that the degree of outsourcing is moderate. The majority of companies that opted for outsourcing did so selectively. Whereas application services make up the largest share of outsourcing, planning and management for the most part remains within the boundaries of the firm.

The main reason for outsourcing IS functions were internal resource deficits compared to external service providers. This implies that IS functions are predominantly seen as necessary resources that are acquired from the most suitable sources which can be either in-house or at the external market. It does not matter whether the assets required to perform an IS function are very firm specific and hence may serve as the basis of a sustained competitive advantage. Moreover, the potential economic risks that may arise from the outsourcing of highly specific IS functions are not reflected by the current sourcing decisions of the SMEs. This requires further research into the specific situation of SMEs. Are SMEs able to build up close relationships with individual (locally situated) external service providers? Are these relationships built on trust and cooperation, which reduces the economic risks of outsourcing? Answers to these questions may explain why no significant relationship could be found between human asset specificity and the degree of outsourcing.

In a sense of "critical social theory" (Lee 1999, p. 31), it may already be critically noted, however, that the practice of small and mid-sized firms to outsource IS functions with a small number of available service providers and with difficulties in evaluating task performance increases the danger of dependency on a single provider (lock-in) and may lead to a loss of control over the service provider over time.

Finally, it should be noted that this study poses a number of limitations that need to be taken into account. First, the sample size can be regarded as small. Second, only a specific business sector of SMEs was surveyed. Research is necessary to determine the extent to which the results may be applied to other industries and whether or not deviations in IS outsourc- 
ing exist with reference to large companies in Germany. ${ }^{9}$ A cross-cultural study could provide information as to whether or not outsourcing behavior in Germanspeaking countries is significantly different from other cultural regions. Third, the division of IS into five functions ignores the fact that these may further be divided into sub-functions. In applications development, for example, the division could reflect the different developmental stages or a division of duties into single modules with diverse requirements for applications development (Alpar and Ein-Dor 1991; Heiskanen et al. 1996). Moreover, the project level may be an appropriate unit of analysis for studying outsourcing decisions (Beath and Walker 1998; Sabherwal 1999). Fourth, the measurement instruments for the uncertainty construct have proven to be extremely heterogeneous. In future studies, the individual indicators should be treated as separate constructs with different causal influences on IS outsourcing (Sutcliffe and Zaheer 1998). Fifth, in this article, relationships were only observed on the macro-level. Each relationship is based on a number of behavioral assumptions on the micro level, i. e. the individual level. These assumptions could potentially be incorporated as separate constructs, and their influence on the model structure could be hypothesized as intermediators or moderators of relationships at the macro-level (Rindfleisch and Heide 1997). Within the framework of TCE theory, the measurement of opportunism or opportunistic behavior, in terms of behavioral uncertainty, as well as the incorporation of trust could exceed the limitations of the neoclassical methodical individualism (Ghoshal and Insead 1996; Noorderhaven 1996). During the exploration of relationships on the individual level, an exploratory research design using case studies could enhance our understanding. In conclusion, it is to be noted that the question of IS outsourcing in small and medium-sized firms is no less exciting than in large companies.

\footnotetext{
9 A study conducted by Alpar and Ein-Dor (1991) in small and mid-sized firms in the USA showed that their needs differ from those of the larger enterprises. Whereas small and mid-sized firms focus on IS quality and reliability, large companies focus on planning and management.
}

\section{References}

Alpar P, Ein-Dor P (1991) Major IS concerns of entrepreneurial organizations. Information \& Management 20:1-11

Alpar P, Saharia AN (1995) Outsourcing information system functions: an organization economics perspective. Journal of Organizational Computing 5(3):197-217

Ang S, Cummings LL (1997) Strategic response to institutional influences on information systems outsourcing. Organization Science 8(3):235-256

Ang S, Straub DW (1998) Production and transaction economies and IS outsourcing: a study of the U.S. banking industry. MIS Quarterly 22(4):535-552

Apte UM, Sobol MG, Hanaoka S et al (1997) IS outsourcing practices in the USA, Japan and Finland: a comparative study. Journal of Information Technology 12:289-304

Aubert BA, Rivard S, Patry M (1996) A transaction cost approach to outsourcing behavior: some empirical evidence. Information \& Management 30(2):51-64

Bagozzi RP, Yi Y (1988) On the evaluation of structural equation models. Journal of the Academy of Marketing Science 16:74-94

Beath CM, Walker G (1998) Outsourcing of application software: a knowledge management perspective. Annual International Conference on System Sciences, IEEE, Hawaii, pp 666-674

Beije PR (1996) Transaction costs and technological learning. In: J Groenewegen J (ed) Transaction cost economics and beyond. Kluwer Academic Publishers, Boston, pp 309-326

Borchers AS (1996) Information technology outsourcing: a test of organizational economic, strategic and political models. School of Business and Enterpreneurship, Nova Southeastern University

Brown C (1997) Examining the emergence of hybrid IS governance solutions: evidence from a single case. Information Systems Research 8(1):69-94

Chin WW (1998a) Exploratory structural equation modeling. structural equation modeling in IS research: ISWorld Net Virtual Meeting Center at Temple University

Chin WW (1998b) Issues and opinion on structural equation modeling. MIS Quarterly 22(1):VIIXVI

Chin WW (1998c) The partial least squares approach for structural equation modeling. In: Marcoulides GA (ed) Modern methods for business research. Lawrence Erlbaum Associates, Hillsdale, pp 295-336

Chin WW, Newsted PR (1999) Structural equation modeling: analysis with small samples using partial least squares. In: Hoyle R (ed) Statistical strategies for small sample research. Sage Publications, pp 307-341

Clemens R, Hauser H-E, Kayser G (2001) Die Konjunktur im Mittelstand zum Jahresanfang 2000-35. Mittelstands-Konjunkturbericht. In: I-M N 143 (ed) Institut für Mittelstandsforschung Bonn, Bonn

Clemons EK, Row MC (1991) Sustaining IT advantage: the role of structural differences. MIS
Quarterly 15(3):275-292

Conner KR (1991) A historical comparison of resource-based theory and five schools of thought within industrial organization economics: do we have a new theory of the firm? Journal of Management 17(1):121-154

Cyert RM, March JG (1963) A behavioral theory of the firm. Prentice-Hall, Englewood Cliffs, p 332

Dearden J (1987) The withering away of the IS organization. Sloan Management Review 28(4):87-91

Demsetz H (1991) The theory of the firm revisited. In: Williamson OE, Winter SG (eds) The nature of the firm - origins, evolutions, and development. New York, pp 159-178

Dernbach W (1997) IT-Ausgründung - ein Schuß nach hinten. Computerwoche (4):14-16

Dibbern J, Güttler W, Heinzl A (2001) Die Theorie der Unternehmung als Erklärungsansatz für das selektive Outsourcing der Informationsverarbeitung. Zeitschrift für Betriebswirtschaft (ZfB) 71(6):675-699

Dierickx I, Cool K, Barney JB (1989) Asset stock accumulation and sustainability of competitive advantage; Comment; Reply. Management Science 35(12):1504-1514

Duncan NB (1998) Beyond opportunism: a resource-based view of outsourcing risk. Annual Hawaii International Conference on System Sciences, IEEE, pp 675-684

Fornell C (1989) The blending of theoretical empirical knowledge in structural equations with unobservables. In: Wold H (ed) Theoretical empiricism: a general rationale for scientific model-building. Paragon House, New York, pp 153174

Foss NJ (1996) Knowledge-based approaches to the theory of the firm: some critical comments. Organization Science 7(5):470-476

Ghoshal S, Insead PM (1996) Bad for practice: a critique of the transaction cost theory. Academy of Management Review 21(1):13-47

Grant RM (1991) The resource-based theory of competitive advantage: implications for strategy formulation. California Management Review 33(3):114-135

Grover V, Cheon MJ, Teng JTC (1994) A descriptive study on the outsourcing of information systems functions. Information \& Management 27(1):33-44

Heinrich L (1969) Zur Frage "Eigenfertigung oder Fremdbezug" bei der Informationsverarbeitung. Schmalenbachs Zeitschrift für betriebswirtschaftliche Forschung 10/11:676-688

Heinzl A (1993) Die Ausgliederung der betrieblichen Datenverarbeitung: eine empirische Analyse der Motive, Formen und Wirkungen. Poeschel, Stuttgart

Heinzl A (1996) Die Evolution der betrieblichen DV-Abteilung: eine lebenszyklustheoretische Analyse. Physica, Heidelberg

Heinzl A, Stoffel K (1993) Die Ausgliederung der betrieblichen Informationsverarbeitung. In: Heinzl A, Weber J (eds) Alternative Organisationskonzepte der betrieblichen Datenverarbeitung. Stuttgart, pp 173-214

Heiskanen A, Newman M, Similä J (1996) Software contracting: a process model approach. International Conference on Information Systems, pp 51-62 


\section{Abstract \\ Jens Dibbern, Armin Heinzl \\ Outsourcing of Information Systems Functions in Small and Medium Sized Enterprises: A Test of a Multi-Theoretical Model}

In this paper determinants of information systems (IS) outsourcing are deduced from transaction cost economic theory, resource-based theory, and power theory. They are summarized in a theoretical framework which is tested using a sample of small and medium sized enterprises (SMEs) in Germany. The results show that internal performance and know-how deficits vis-à-vis external service providers are key determinants that explain why different IS functions are outsourced to varying degrees in SMEs. Moreover, the determinants of IS functions were found to partially differ between IS functions.

Revised reprint of an article from WIRTSCHAFTSINFORMATIK 43(4)2001: 339-350.

Keywords: Information systems outsourcing, Small and medium sized enterprises (SMEs), Transaction cost economic theory, Resource-based theory, Power theory, Structural equation modeling, Partial least squares, Empirical study
Knudsen C (1995) Theories of the firm, strategic management, and leadership. In: Montgomery CA (ed) Resource-based and evolutionary theories of the firm: towards a synthesis. Boston, pp 179-217

Krcmar H (1992) Leise Töne im Information Management des Mittelstands. Information Management 7(4):79-83

Krcmar H (1997) Informationsmanagement. Springer, Heidelberg

Lacity MC, Hirschheim RA (1993) Information systems outsourcing: myths, metaphors, and realities. Wiley, pp XIV, 273

Lacity MC, Willcocks LP, Feeny DF (1995) IT outsourcing: maximize flexibility and control. Harvard Business Review (May-June), pp 84-93

Lacity MC, Willcocks LP, Feeny DF (1996) The value of selective IT sourcing. Sloan Management Review 37(3):13-25

Langlois RN (1995) Capabilities and coherence in firms and markets. In: Montgomery CA (ed) Resource-based and evolutionary theories of the firm: towards a synthesis. Boston, pp 71-100

Lee AS (1999) Rigor and relevance in MIS research: beyond the approach of positivism alone. MIS Quarterly 23(1):29-33

Lee B, Barua A, Whinston AB (1997) Discovery and representation of causal relationships in MIS research: a methodological framework. MIS Quarterly 21(1):109-136

Loh L (1993) The economics and organization of information technology governance: sourcing strategies for corporate information infrastructure. Massachusetts Institute of Technology

Loh L, Venkatraman N (1992) Determinants of information technology outsourcing: a cross-sectional analysis. Journal of Management Information Systems 9(1):7-24

Lucacs M (1998) European outsourcing markets and trends. International Data Corporation (IDC), \#P04E

Mata FJ, Fuerst WL, Barney JB (1995) Information technology and sustained competitive advantage: a resource-based analysis. MIS Quarterly 19(4):487-505

McLellan KL, Marcolin BL, Beamish PW (1995) Financial and strategic motivations behind IS outsourcing. Journal of Information Technology 10:299-321

Mertens P, Knolmayer G (1998) Organisation der Informationsverarbeitung: Grundlagen Aufbau - Arbeitsteilung. Wiesbaden

Morgan G (1996) Images of organization. Newbury Park

Murphy C, Ker S, Chen, S (1999) U.S. and worldwide outsourcing markets and trends. International Data Corporation (IDC), \#19322

Nam K, Rajagopalan S, Rao HR, Chaudhury A (1996) A two-level investigation of information systems outsourcing. Communications of the ACM 39(7):36-44

Noorderhaven NG (1996) Opportunism and trust in transaction cost economics. In: Groenewegen J (ed) Transaction cost economics and beyond. Kluwer Academic Publishers, Boston, pp 105-128

OECD (2000) Information Technology Outlook: 2000. Paris

Peter J (1981) Reliability: a review of psychometric basics and recent marketing practices. Journal of Marketing Research 16(February):6-17

Pfeffer J (1981) Power in organizations. Pitman Pub., Marshfield, pp XIV, 391

Poppo L, Zenger T (1998) Testing alternative theories of the firm: transaction cost, knowledgebased, and measurement explanations for make-or-buy decisions in information services. Strategic Management Journal 19:853-877

Rindfleisch A, Heide JB (1997) Transaction cost analysis: past, present, and future applications. Journal of Marketing 61(4):30-54

Rumelt RP, Schendel D, Teece DJ (1991) Strategic management and economics. Strategic Management Journal 12:5-29

Sabherwal R (1999) The role of trust in outsourced IS development projects. Communications of the ACM 42(2)

Sambamurthy V, Zmud RW (1999) Arrangements for IT governance: a theory of multiple contingencies. MIS Quarterly 23(3):261-290

Sobol MG, Apte UM (1995) Domestic and global outsourcing practices of America's most effective IS users. Journal of Information Technology 10:269-280

Spitta T (1998) IV-Controlling in mittelständischen Industrieunternehmen - Ergebnisse einer empirischen Studie. WIRTSCHAFTSINFORMATIK 5:424-433

Sutcliffe KM, Zaheer A (1998) Uncertainty in the transaction environment: an empirical test. Strategic Management Journal 19(1):1-23

Teece DJ, Rumelt RP, Dosi G, Winter SG (1994) Understanding corporate coherence: theory and evidence. Journal of Economic Behavior and Organization 23:1-30

Teng JTC, Cheon MJ, Grover V (1995) Decisions to outsource information systems functions: testing a strategy-theoretic discrepancy model. Decision Sciences 26(1):75-103

Tushman M (1977) A political approach to organizations: a review and rationale. Academy of Management Review 2(2):206-216

Willcocks L, Fitzgerald G, Lacity M (1996) To outsource IT or not? Recent research on economics and evaluation practice. European Journal of Information Systems 5(3):143-160

Williamson OE (1975) Markets and hierarchies, analysis and antitrust implications: a study in the economics of internal organization. Free Press, New York, pp xvii, 286

Williamson OE (1981) The economics of organization: the transaction cost approach. American Journal of Sociology 87(3):548-577

Williamson OE (1985) The economic institutions of capitalism: firms, markets, relational contracting. Free Press, Collier Macmillan, pp xiv, 450

Williamson OE (1990) Transaction cost economics. In: Schmalensee R, Willig RD (eds) Handbook of Industrial Organization. Amsterdam, pp 135-182

Wold H (1989) Introduction to the second generation of multivariate analysis. In: Wold H (ed) Theoretical empiricism: a general rationale for scientific model-building. Paragon House, New York, pp VII-XL 